\title{
Prevalence of Osteoporosis and Osteopenia Status among Population of Central Nepal using Calcaneal Ultrasonography Method
}

\author{
Satyajit Bagudai, ${ }^{1}$ Hari Prasad Upadhyay ${ }^{2}$ \\ ${ }^{1}$ Department of Physiology, ${ }^{2}$ Department of Community Medicine, College of Medical Sciences, Bharatpur-10, \\ Chitwan, Nepal.
}

\begin{abstract}
Background: A recent worldwide upsurge in the fracture incidence due to osteoporosis has underlined this underdiagnosed and undertreated condition. An awareness regarding the preventive, curative and rehabilitative care as well as a proper health policy is the need of hour. This requires a proper database of prevalence rate. This study aimed to find out the prevalence of osteoporosis and osteopenia by screening the calcaneal bone health status in an apparently healthy population of Nepal. Methods: A cross sectional study was conducted among 465 apparently healthy subjects of either gender in three tertiary care health centers of Nepal for bone mineral density measurement by calcaneal ultrasonography. Results: The mean \pm SD of age among 465 patients was $45.47 \pm 14$ years, including $43.2 \%$ male and $56.8 \%$ females. The prevalence of osteoporosis and osteopenia was $22.4 \%$ and $60.6 \%$ respectively. Conclusions: We found the prevalence of osteoporosis and osteopenia in Nepalese population to be high in comparison to other countries. Osteoporosis and osteopenia are associated significantly with increasing age in either gender. There is no significant association of osteoporosis and osteopenia with gender as well as geographical location. These findings will help in creating a proper database of this condition in Nepal, helping the population, physicians as well as policy makers to have a proper address to this global emerging health problem.
\end{abstract}

Keywords: bone mineral density; calcaneal ultrasonography; osteoporosis; osteopenia.

\section{INTRODUCTION}

Osteoporosis is a condition of decreased bone strength with a characteristic demineralization and deterioration of skeletal microarchitecture. ${ }^{1}$ Histologic section of bone on osteoporosis reveals a normal degree of mineralization but a reduction in the volume of bone, specifically trabecular bone. ${ }^{2}$ This condition frequently leads to an increased risk of bone fractures most specifically at hip, vertebra and wrist. $^{3}$ Many studies have shown a good evidence that the risk of osteoporosis and fracture increases with age more specifically in females. ${ }^{4,5}$ Lack of any symptoms for a long time keeps this disease undiagnosed for a long time and is only detected at the time of fracture. Recent studies have pointed about the growing concern regarding the socioeconomic burden posed by these due to an ever increasing ageing population specifically in the developing nations of Asia. ${ }^{6,7}$ It has been expected that by $2050,45 \%$ of all osteoporotic hip fracture worldwide will occur in Asia., ${ }^{6,7}$ Thus a greater need of detecting this disease early and treating it has been realized. Bone mineral density is the most important parameter in the early diagnosis of osteoporosis and osteopenia of adult age group of more than 20 years (when peak bone mass is achieved. ${ }^{8}$ This provides a numerical estimate of individuals bone mass. ${ }^{9}$ With various techniques available to measure bone density, quantitative ultrasound technology has been proven to deliver a highly accurate and safe measurement technique of bone density. ${ }^{10,11}$ This inexpensive method is also well suited for a community based large scale screening of osteoporosis. Various studies have been done worldwide to find the societal burden of osteoporosis in different population by this method., ${ }^{9-15}$ Very limited studies, irrespective of geographical location have been conducted in Nepalese population to find out the prevalence of osteoporosis. ${ }^{16}$ With a greater need for prevention and control of osteoporosis, this screening survey was conducted to find the prevalence of osteoporosis in Nepalese population in a multicentric approach.

\section{METHODS}

This cross sectional study was carried out at the orthopedic outpatient department of College of Medical Sciences (COMS), Bharatpur, Manipal College of Medical Sciences, Pokhara and Siddhartha city hospital, Bhairahawa with a random sample population present in the hospital and medical college after getting an appropriate informed consent from the persons under the study group. The study was carried out between July to

Correspondence: Dr. Satyajit Bagudai, Department of Physiology, College of Medical Sciences-Teaching Hospital, Bharatpur-10, Chitwan, Nepal. Email: sbagudai@gmail.com. Phone: +9779821241241. Article received: 2019-05-19. Article accepted: 2019-11-24. 
Bagudai et al. Prevalence of Osteoporosis and Osteopenia Status among Population of Central..

September 2018.The study included healthy males and females of more than 20 years of age who were free from apparent illness, present in the institute/ hospital and willing to participate in the screening procedure. From the historical information obtained, those having any type of chronic diseases or on biphophonates, thyroxin, steroids, immunosuppresives, antiepileptics, calcitonin therapy were excluded from the study. All the participants were subjected to BMD measurements of the calcaneus bone by Quantitative Ultrasound bone densitometer by the same technician and instrument (SONOST 20000) to avoid the bias. The results of BMD were analyzed on the basis of $\mathrm{T}$ score.

According to the WHO diagnostic criteria, osteoporosis was defined in terms of a $\mathrm{T}$ score below or equal to -2.5 , osteopenia with a $\mathrm{T}$ score between -2.5 and -1 and $\mathrm{T}$ score more than or equal to -1 is considered as normal. ${ }^{17}$ In 2012 a study conducted by Sharma et $\mathrm{al}^{15}$ showed the prevalence of osteoporosis to be $26.2 \%{ }^{16}$ Based upon this prevalence and using the formula $n=z^{2} \mathrm{pq} / \mathrm{e}^{2}$ (the $z$-score value at $95 \% \mathrm{CI}$ is 1.96 , with an allowable error of 0.1 ), the optimal sample size was calculated to be $83 \times 3=249$. For a better reflection we took the sample size of 465 in total from three place. Simple random sampling technique was used to select the sample. Collected data was checked for completeness and coded. Data was entered in EpiData 3.1 followed by data analysis using statistical software SPSS (version 17). Results was presented by using descriptive and inferential statistics. In descriptive statistics result was presented in the table, figure, frequency, percent, mean, standard deviation. In inferential statistics to find the association between Bone Mineral Density with other related variables Chisquare test was used. Also, to find the nature of relation ship between bone mineral density with age correlation was find. The level of significance in this study is considered as $5 \%$.

\section{RESULTS}

Table 1 shows the sociodemographic information of the respondents. Majority of the respondents were in age group 30-40 years and minimum were in age group less than 20 years. The mean $\pm \mathrm{SD}$ of age was $45.47 \pm 14.71$ Years. The minimum and maximum age was 10 and 80 years. Majority of the respondents were female by gender and more respondents were from Bhairawa side. The age wise distribution of osteoporosis and osteopenia prevalence in the study group (Table 2).

The prevalence of osteoporosis and osteopenia was $22.4 \%$ and $60.6 \%$ (Table 3 \& Figure 1). Table 5 shows the correlation between bone mineral density and age, which shows that there is negative

\begin{tabular}{|c|c|c|}
\hline Variable & Frequency & Percentage \\
\hline \multicolumn{3}{|c|}{ Age (year) } \\
\hline$<20$ & 10 & 2.2 \\
\hline $20-30$ & 61 & 13.1 \\
\hline $30-40$ & 123 & 26.5 \\
\hline $40-50$ & 110 & 23.7 \\
\hline $50-60$ & 81 & 17.4 \\
\hline $60-70$ & 63 & 13.5 \\
\hline$>70$ & 17 & 3.7 \\
\hline \multicolumn{3}{|c|}{ Mean \pm SD , Min(Max)Years $45.47 \pm 14.71,10(80)$} \\
\hline \multicolumn{3}{|c|}{ Gender } \\
\hline Male & 201 & 43.2 \\
\hline Female & 264 & 56.8 \\
\hline \multicolumn{3}{|l|}{ Address } \\
\hline Chitwan & 114 & 24.5 \\
\hline Pokhara & 168 & 36.1 \\
\hline Bhairawa & 183 & 39.4 \\
\hline
\end{tabular}

\begin{tabular}{|c|c|c|c|c|}
\hline $\begin{array}{l}\text { Table } 2 \\
\text { osteope }\end{array}$ & $\begin{array}{l}\text { 2. Age wis } \\
\text { enia. } n=465\end{array}$ & se distribu & on of os & oporosis anc \\
\hline Age & Oesteopo & rosis & Oesteope & nia \\
\hline (years) & Male (\%) & Female (\%) & Male (\%) & Female $(\%)$ \\
\hline$<20$ & 5.4 & 0 & 2.4 & 2.3 \\
\hline $20-30$ & 5.4 & 0 & 17.5 & 16.9 \\
\hline $30-40$ & 13.5 & 4.3 & 19 & 34.9 \\
\hline $40-50$ & 21.6 & 8.7 & 23 & 22.7 \\
\hline $50-60$ & 16.2 & 41.3 & 21.4 & 14 \\
\hline $60-70$ & 24.3 & 32.6 & 14.3 & 7.6 \\
\hline$>70$ & 13.5 & 13 & 2.4 & 13 \\
\hline
\end{tabular}

Table 3. Prevalence of osteoporosis and osteopenia according to the bone mineral density. $n=465$

\begin{tabular}{|lcc|}
\hline Variable & Frequency & Percentage \\
Result & 79 & 17 \\
Normal & 104 & 22.4 \\
Osteoporosis & 282 & 60.6 \\
\hline Osteopenia & \\
\hline
\end{tabular}

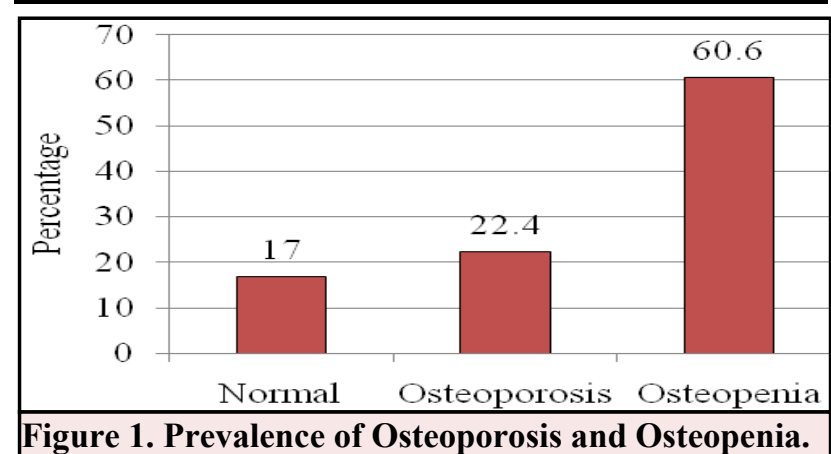

correlation between BMD and age. This result was found to be statistically significant ( $p$-value $<0.001$ ) (Table 4 and Figure 2). Mean and SD of Bone 
Bagudai et al. Prevalence of Osteoporosis and Osteopenia Status among Population of Central..

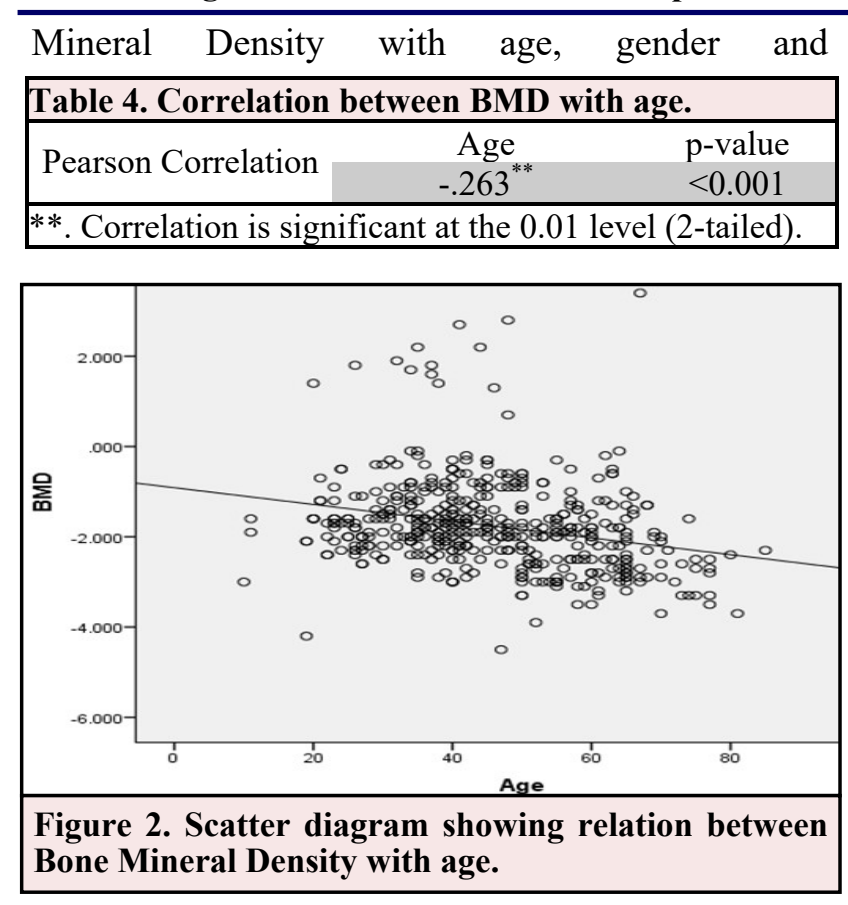

Geographical location is shown in (Table 5).

\begin{tabular}{|lcc|}
\hline \multicolumn{3}{|c|}{$\begin{array}{c}\text { Table 5. Mean and SD of Bone Mineral Density with } \\
\text { age, gender and Geographical location. }\end{array}$} \\
\hline \multicolumn{3}{|c|}{ Bone Mineral Density } \\
Variable & Mean & SD \\
Age & & \\
$<20$ & -1.83 & 1.4 \\
$20-30$ & -1.68 & 0.72 \\
$30-40$ & -1.43 & 0.97 \\
$40-50$ & -1.53 & 1.08 \\
$50-60$ & -2.15 & 0.75 \\
$60-70$ & -2.03 & 1.08 \\
\hline 70 & -2.81 & 0.54 \\
Gender & & \\
Male & -1.75 & 0.93 \\
Female & -1.75 & 1.05 \\
Geographical location & & \\
Chitwan & -1.62 & 1.12 \\
Pokhara & -1.74 & 1 \\
Bhairawa & -1.85 & 0.91 \\
\hline
\end{tabular}

Table 6 showed the association and prevalence between Bone Mineral Density and sociodemographic variable reflecting the significant association between age with bone mineral density. The prevalence of osteoporosis was high among old age people. There is no association of gender and geographical location with bone mineral density.

\section{DISCUSSION}

The recent increase in the magnitude of the fractures along with the amount of morbidity and mortality as well as the economic burden it carries has created a large interest to find out the societal burden of osteoporosis in many communities worldwide. A precise data regarding this is still
Table 6. Association between BMD with selected variable.

\begin{tabular}{|llllll|}
\hline Variable & $\begin{array}{c}\text { Osteo- } \\
\text { porosis }\end{array}$ & $\begin{array}{c}\text { Prevalence } \\
\text { Osteo- }\end{array}$ & Normal & $\chi^{2}$ & p-value \\
Age & & & & & \\
$<20$ & $2(20)$ & $7(70)$ & $1(10)$ & & \\
$20-30$ & $4(6.6)$ & $50(82)$ & $7(11.5)$ & & \\
$30-40$ & $9(7.3)$ & $84(68.3)$ & $30(24.4)$ & 110. & $<0.001 *$ \\
$40-50$ & $14(12.7)$ & $66(60)$ & $30(27.3)$ & 99 & \\
$50-60$ & $33(40.7)$ & $44(54.3)$ & $4(4.9)$ & & \\
$60-70$ & $29(46)$ & $27(42.9)$ & $7(11.1)$ & & \\
$>70$ & $13(75.6)$ & $4(23.5)$ & - & & \\
Gender & & & & & \\
Male & $46(23.4)$ & $118(58.7)$ & $36(17.9)$ & 0.56 & 0.76 \\
Female & $57(21.6)$ & $164(62.1)$ & $43(16.3)$ & & \\
Geographical location & & & \\
Chitwan & $20(17.5)$ & $73(64)$ & $21(18.4)$ \\
Pokhara & $38(22.6)$ & $101(60.1)$ & $29(17)$ & 2.40 & 0.661 \\
Bhairawa & $46(25.1)$ & $108(59)$ & $29(15.8)$ \\
\hline *Significant at the 0.001 level (2-tailed) & & \\
\hline
\end{tabular}

lacking in Nepalese population at present. Few data about the prevalence of osteoporosis among postmenopausal woman from some areas has been reported. But a multicentric approach involving a higher sample size which can show a better reflection of this condition is still lacking. In our study, we selected the sample from different areas of Nepal with population of 465 , of either gender. Whereas most of the other studies have been done with an older population group, we selected a wider range of age group to find out the prevalence of this problem in a larger cross section of the society. ${ }^{16,18,19}$ Our study showed a higher prevalence of osteopenia $(60.6 \%)$ than osteoporosis $(22.4 \%)$ irrespective of gender and age according to the BMD $\mathrm{T}$ score. The overall prevalence rate of osteoporosis was higher than Indian and Chinese population in comparison, the two populous countries surrounding Nepal. ${ }^{18-20}$ When compared with European countries, ${ }^{21}$ where most of the studies have been done with more than 50 year population, our prevalence rate was higher compared with the same aged population. We could not find any significant correlation between osteoporosis with a specific gender unlike other studies where females are having a significant correlation with osteoporosis than males. ${ }^{10,18,22,23}$

We also found that there is a significant correlation between the increasing age with the prevalence of osteoporosis among both the gender groups as like other studies from different parts of the world. ${ }^{18,24}$ We could not find any significant association $(p=>0.05)$ between the geographical area with the pattern of osteoporosis. It signifies a uniform pattern of this burden prevailing among the different communities within Nepal. There is considerable evidences showing osteopenia to be the preceding 
condition before osteoporosis and both these conditions are the result of decreased bone mass. A proper understanding of bone mineral density is paramount for the preventive as well as curative and rehabilitative aspects of osteoporosis. BMD correlates strongly with bone strength, accounting for $75 \%-85 \%$ of the variance in the ultimate strength of bone tissue. Reported differences have shown that variations in bone structure and micro architecture can create an alteration of bone health between ethnic groups. ${ }^{26-28}$ The racial variation of bone mass even if contributed by the difference in life style, still the genetic factors also carries a high degree of importance. An accumulating information has established that $50-90 \%$ of BMD variation can be explained by genetic factor. ${ }^{29-31}$ Studies to show the differential genetic influence on the variations of BMD in Asian and Caucasian population has been done by Jian et al and Deng et al using the same estimation method and same type of sample. ${ }^{32,33}$ Jian et al found the estimates of heritabilities of 0.44 and 0.77 for spine and hip BMD respectively in Chinese population and 0.86 and0.84 in Caucasian population. Lei et al have done a comparative study on the polymorphism of four candidate BMD gene among Chinese and other population and has showed a significant ethnic differentiation on four candidate genes. ${ }^{34}$ Dvornyk et al investigated an comparative study for the association of six markers for five candidate genes with BMD variations in Chinese and Caucasian population where they found that ethnicity seems to influence the association outcomes as well as the total population BMD variations in both gender. ${ }^{35}$ Inspite of these works, the definite conclusion regarding the association of BMD with ethnicity is still yet to be finalized because of the limited studies and the imperfect study designs. As per our findings, age has influenced the prevalence of osteoporosis and osteopenia.

There is a significant trend of decrease in bone density with the increase age in both gender. A study by Ahuja in a necropsy study has also reported a $44 \%$ cases of osteopenia in persons of 50 years of age in either gender, specifically in trabecular bones. ${ }^{36} \mathrm{He}$ also reported a $6 \%$ loss of bone per decade after $3^{\text {rd }}$ decade. Lekamwasam et al has reported from his study in Srilanka, that the prevalence of osteoporosis is lesser in males than females, but it increases with advancing age as like females. ${ }^{37}$ Marwaha et al found the prevalence of osteoporosis increased with age in females but not in males. ${ }^{38}$ In our study we found a higher prevalence of osteoporosis in males in 20-50 years of age group whereas the prevalence of osteoporosis was higher in females in 50-70 age group along with a tendency of increase of prevalence with advancing age. A probable correlation of decreasing testosterone and estrogen with advancing age in males and females has been shown by many studies. ${ }^{39-41}$ But keeping in view of these gender equality with advancing age, a possible association of nutritional factors like protein calorie malnutrition, level of vitamin $\mathrm{D}$ and calcium is high. Many studies specifically from India has reported an early onset osteoporosis in women. The National Institute of Nutrition in India report states that Indian women suffers from the early onset osteoporosis due to the deficient protein calorie as well as calcium in their diet. ${ }^{42}$ In the background of an early onset, prolonged and exclusive breastfeeding which is prevalent both in Nepal and India, it is important to look into the bone status of these population. Achievement of peak bone mass as an adult after 20 years of age is imperative to maintain a higher bone mass in later life, which is needed to decrease the bone mass around the time of menopause. Due to the above facts it is highly possible that the young adult women of Nepal might not be attending their peak bone mass adequately. This needs a large scale survey of the bone mass of young adult females. The role of calcium and vitamin $\mathrm{D}$ has been underlined by many studies as an association factor with osteoporosis. $^{43,44}$

Calcium and vitamin D intake in Nepalese population may be much lower than western countries even if the recommended daily allowance of calcium and vitamin D is lower than their western counterparts. This assessment with the scenario of Nepal is also a need of the hour. Estrogen deficiency is also a major determinant of osteoporosis specifically in post menopausal women. Conversion of adrenal androgen to estrogen in peripheral adipose tissue is an important source of estrogen in postmenopausal women. In this context, a lesser body weight with a lesser body fat specifically in the lower socio economic background may be a contributing factor of osteoporosis. It has also been found that girls of developing countries reach the menarche later than those of developed countries, most probably due to the nutritional factors. This can create an state of estrogen deficiency in the female throughout her fertile period. Muscle contraction considered as a potent source of load upon the skeleton irrespective of the weight bearing bones. ${ }^{45}$ With approved differences in lean body mass, there is a high likelihood of muscle force and power between ethnic groups. This may contribute to the difference in BMD as well as the size ,shape of the bony architecture. Preliminary reports are coming from EMAS showing an ethnic relationship between the force, power and age of the muscle. ${ }^{46,47}$ This factor is highly pertinent with respect to a developing nation like Nepal, where the body muscle mass may reside towards the lower part of Asian race. In this aspect some future studies not only relating to the 
measurement of the muscle mass or cross sectional area but also quantifying the functional aspects muscle strength by the dynamic tests (grip force, jumping mechanography, dynamometry, and electromyography) can give us a more strong and comprehensive confirmation regarding these association.

\section{CONCLUSIONS}

In our study we tried to identify the prevalence of a worldwide emerging public health problem like osteoporosis with a proven standardized method. More studies of this type is needed to establish the bone density norms for Nepalese males and females of different age group and sociocultural background. This study will not only allow the individualized diagnosis of osteopenia and osteoporosis but also will create a high degree of specific awareness among the physician and population in Nepal. Simultaneously it will help the appropriate authority to start a policy regarding the preventive, curative and rehabilitative aspects of this emerging problem. A more detailed clinical study can be done further to include even a higher sample size involving even more widespread geographical area to find the etiological factors for the early onset and the high male prevalence rate in Nepal.

\section{ACKNOWLEDGEMENTS}

We are thankful to Mr. Mahesh Kishor Mishra (Micro medical services) for all the support needed in our work. Also, we are grateful to the authorities of the centers (Manipal Medical College, Pokhara and Siddhartha Hospital, Bhairahawa) for giving the due permission to conduct the study.

\section{Limitations}

We have not included the details of other relevant parameters like fracture incidence, smoking and alcohol intake, menopausal status, status of parity, nutrition, Calcium and Vit.D status, BMI, muscle mass as well as physical activity and exercisein this study which could have given a further comprehensive analysis of this condition with respect to $\mathrm{Ne}$ pal.

\section{Conflict of interest: None}

\section{REFERENCES}

1. Dennis Kasper, Anthony Fauci, Stephen Hauser, Dan Longo, J Larry Jameson, Joseph Loscalzo.Principles of Internal Medicine 19e

2. Nelson Textbook of pediatrics $17 \mathrm{e}$

3. Randell A, Sambrook PN and Nguyen TV. Direct clinical and welfare costs of osteoporotic fractures in elderly men and women. Osteoporos Inter. 1995;5:427.

4. Najam R, Huda N. Assessment of Osteoporosis in Post Menopausal Women: A Clinical Study. NJOG 2011 Nov-Dec;6(2):11-13

5. Kanis JA, Melton LJ, Christiansen $\mathrm{C}$ et al. The diagnosis osteoporosis. J Bone Miner Res 1994;9:1137-41

6. International Osteoporosis Foundation (2009) The Asian Audit: Epidemiology, costs and burden of osteoporosis in Asia 2009. www.iofbonehealth.org.

7. Gullberg B, Johnell O, Kanis JA (1997) Worldwide projections for hip fracture. OsteoporosInt 7:407

8. Cooper C, Campion G, Melton LJ, $3^{\text {rd }}$ (1992) Hip fractures in elderly: a world-wide projection. OsteoporosInt 2:285.

9. Agarwal T, Verma AK. Cross sectional study of osteoporosis among women. Med J Armed Forces India 2013;69:168-71

10. Marin F, Gonzalez-Macias J, Diez-Perez A, Plalma S, Delgo Rod. J Bone Miner Res 2016;21(7):1126-35.

11. Guglielmi G, de Terlizzi F. Quantitative ultrasound in the assessment of osteoporosis. Eur J Radiol 2009;71(3):425-31.

12. Maggi S, Noale $M$, Giannini $S$, et al. Quantitative heel ultrasound in a population based study in Italy and its relationship with fracture history: The ESOPO study. OsteoporosInt 2006; 17(2):237-44.

13. Sharma S, Tandon VR, Mahajan A, Kour A, Kumar D. Preliminary screening of osteoporosis and osteopenia in urban women from Jammu using calcaneal QUS. Indian J Med Sci2006;60:183-9.

14. Lin JD, Chen JF, Chang HF, HOC. Evaluation of bone mineral density by quantitative ultrasound of bone in 16,862 subjects. $\mathrm{Br} \mathrm{J}$ Radiol 2001;74(883):602-6.

15. Arslantas D, Metintas S, Unsal A, Isikli B, Kalyoncu C, Arslantas A. Prevalence of osteoporosis in middle Antolian population using calcaneal ultrasonography method. Maturitas 2008;59(3):234-41.

16. Sharma DK, Dhakal S, Aryal B. Prevalence of Osteoporosis among Middle aged women in Chitwan District of Nepal. International Journal of Pharmaceutical \& Biological Archives 2012;3(4):779-782.

17. WHO Scintific Group on the prevention and management of Osteoporosis:WHO Technical Report Series 921,WHO.

18. Kaushal N, Vohora D, Jalali RK, Jha S, Prevalence of osteoporosis and osteopenia in an apparently healthy Indian population - a crosssectional retrospective study. Osteoporosis and Sarcopenia 2018;4(2):53-60.

19. Hans D, Dargent Molina, Shott AM, et al. Ultrasonographic heel measurements predict 
hip fracture in elderly women: The EPIDOS prospective study. Lancet 1996;348:511-4

20. Wang Y ,Tao Y, Hyman ME, et al. (2009).Osteoporosis in China. OsteoporosInt 20:1651.

21. Facts and Statistics/International osteoporosis foundation. https://www.iofbonehealth.org/facts -statistics.

22. Naganathan V, Sambrook P. Gender difference in volumetric bone density: a study of oppositesex twins. OsteoporosInt2003;14:564-9

23. Nieves JW, Formica C, Ruffing J, Zion M, Garrett P, Lindsay R, et al. Males have larger skeletal size and bone mass than females, despite comparable body size. J Bone Miner Res 2005;20:529-35

24. Agrawal T, Verma AK. Cross sectional study of osteoporosis among women. Med J Armed Forces India 2013;69:168-71.

25. Melton LJ, Chao EYS, Lane J. Biomechanical aspects of fracture. In Riggs BL, Melton LJ (eds). Osteoporosis Etiology, diagnosis and management New York. Rven Press; 1988: 111 -31 .

26. Lei SF, Chen Y, Xiong DH, Li LM, Deng HW. Ethnic difference in osteoporosis related phenotypes and its potential underlying genetic determination. J Musculoskeletal Neuronal Interact 2006;6: 36-46.

27. Zengin A, Prentice A, W ard KA. Ethnic differences in bone health. Front Endocrinol (Lausanne) 2015;6:24

28. Zengin A, Prentice A, Ward KA. Ethnic differences in bone health. Frontiers in Endocrinology. March 2015(Volume6), Article 24/1-6

29. Wu XP, Lio EY, Dai RC, Zhang H. A comparison study of the reference curves of bone mineral density at different skeletal sites in native Chinese, Japanese and Americal Caucasian women. Calcif Tissue Int2003;73:122-132.

30. Ross PD, McClung M, Thompson D, Wasnich RD. Body size accounts for most differences in bone density between Asian Caucasian women. The EPIC (Early Post menopausal Interventional Cohort) study group. Calcif Tissue Int1996;59:339-343

31. Duncan EL, Cardon LR, Sinsheimer JS, Wass JA, Brown MA. Site and gender specificity of inheritance of bone mineral density. J Bone Miner Res 2003;18:1531-1538.

32. Jian WX, Long JR, LiMX, Liu XH, Deng HW. Genetic determination of variation and covariation of bone mineral density at the hip and spine in a Chinese population. $\mathrm{J}$ Bone Miner Metab2005;23:181-185.

33. Deng HW, Stegman HR, Davies KM, Conway $\mathrm{T}$, Recker RR. Genetic determination of variation and covariation of peak bone mass at the hip and spine. J ClinDensitom1999;2:251263.

34. Lei SF, Chen Y, Xiong DH, Li LM, Deng HW. Ethnic difference in Osteoporosis- related phenotypes and its potential underlying genetic determination. J Musculoskelet Interact 2006;6 (1):36-46.

35. Dvornyk V, Liu XH, Shen H, Lei SF, Zhao LJ, Huang QR, Qin YJ, Jiang DK, Long JR, Zhang YY, Gong G, Recker RR, Deng HW. Differentiation of Caucasians and Chinese at bone mass candidate genes: implication for ethnic difference of bone mass. Ann Hum Genet 2003;67:216-227.

36. Ahuja M. Normal variation in the density of selected human bone in North India: A Necropsy Study. J Bone Joint Surgery $\mathrm{Br}$ November 1969 Vol 51-B no.4719-35.

37. Lekamwasam S, Wijayaratne L, Rodrigo $M$ et al (2009). Prevalence and determinants of osteoporosis among men aged 50 years or more in Srilanka: a community- based cross sectional study. Arch Osteoporos 4:79-84.

38. Marawah RK, Tandon N, Garg MK et al (2011). Bone health in healthy Indian population aged 50 years and above. OsteoporosInt 22:2829-2836.

39. Fink HA, Ewing SK, Ensrud KE et al (2006). Association of testosterone and estradiol deficiency with osteoporosis and rapid bone loss in older men. J clinEndocrinolMetab 91:3908-3915.

40. Meier C, Nguyen Tv, Handelsman DJ et al (2008) Endogenous sex hormones and incident fracture risk in older men: the Dubbo Osteoporosis Epidemiology Study . Arch Intern Med 168:47-54.

41. Kenny AM, Prestwood KM, Marcello KM et al (2000) Determinants of bone density in healthy older men with low testosterone level. J GerontolABiolSci 55:M492-M497.

42. National Institute of Nutrition Studies Research Highlights, April 2008.

43. Paul TV, Thomas N, Seshadri MS, Oommen R, Jose A, Mahendri NV. Prevalence of osteoporosis in ambulatory post menopausal women from semiurban region in southern India: relationship to calcium nutrtition and vitamin D status. EndocrPract2008;14:665-71

44. Shatrugna V, Kulkarni B, Kumar PA, Rani KU, Balakrishna N. Bone status of Indian women from a low economic group and its relationship to the nutritional status. OsteoporosInt2005;16:1827-35.

45. Frost H. Bone "mass" and the "mechanostat": a proposal. Anat Rec (1987) 219:1-910.1002/ ar.1092190104

46. Ward K, Jeffery M, Pye S, Adams J, Boonen S, Vanderschueren D, et al. Abstracts of the osteoporosis conference 2010. November 28- 
Bagudai et al. Prevalence of Osteoporosis and Osteopenia Status among Population of Central..

December 1, 2010. Liverpool, United Kingdom. OsteoporosInt (2010) 21:S443-51810.1007/ s00198-010-1388-x

47. Jeffrey M. Age-related change and ethnic differences in neuromuscular function. 8th International Workshop For Musculoskeletal \& Neuronal Interactions. Ipswich; (2012).

Citation: Bagudai S, Upadhyay HP. Prevalence of Osteoporosis and Osteopenia Status among Population of Central Nepal using Calcaneal Ultrasonography Method. JCMS Nepal. 2019; 15(4):249-55. 